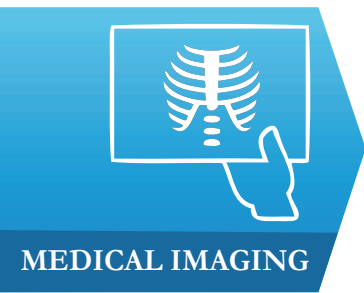

Local staging of prostate cancer with multiparametric-MRI: accuracy and inter-reader agreement

Cristian Popiţa ${ }^{1,2}$, Anca-Raluca Popiţa ${ }^{1,2}$, Adina Andrei ${ }^{3}$, Adriana Rusu ${ }^{2}$, Bogdan Petruț,2,4, Gabriel Kacso ${ }^{2}$, Cătălina Bungărdean ${ }^{5}$, Nicolae Bolog $^{6}$, Ioan Coman ${ }^{2,7}$

1) Radiology Department, Ion Chiricuţă Oncology Institute, ClujNapoca, Romania

2) Iuliu Haţieganu University of Medicine and Pharmacy, Cluj-Napoca, Romania

3) Radiology Department, Emergency Children's Hospital, Cluj-Napoca, Romania

4) Urology Department, Ion Chiricuţă Oncology Institute, Cluj-Napoca, Romania

5) Pathology Department, Clinical Municipal Hospital, Cluj-Napoca, Romania

6) Phoenix Swiss Med, Münchenstein, Switzerland

7) Urology Department, Clinical Municipal Hospital, Cluj-Napoca, Romania

\begin{abstract}
Background. The accuracy of prostate cancer local staging at the time of diagnosis directly influences patient prognosis and treatment.

Aim. To evaluate the diagnostic performance and interobserver variability of $m p-M R I$ in local staging of prostate cancer, using the histopathologic findings at prostatectomy as the reference standard.

Methods. Fifty patients (mean age $64.4 \pm 7.2$ ) with biopsy confirmed prostate cancer were included in this prospective study. All patients were examined with mp-MRI before radical prostatectomy and images were read by three independent radiologists. Sensitivity (Se), specificity $(\mathrm{Sp})$, positive predictive value (PPV), negative predictive value (NPV), and accuracy rate were calculated and compared for all three readers. Interobserver agreement was evaluated using Kappa Cohen coefficient of agreement.
\end{abstract}

Results. The overall Se, Sp, PPV, NPV and accuracy rates for detecting extraprostatic tumor extension (EPE) ranged between 76.5-94.1\%, 45.5-84.9\%, $43.8-76.2 \%, 83.3-96.6 \%$ and $58-88 \%$. For evaluation of seminal vesicle invasion (SVI), the overall Se, Sp, PPV, NPV and accuracy rates ranged between 57.1$85.7 \%, 86.1-97.7 \%, 40.0-85.7 \%, 92.5-97.7 \%$ and $82-96 \%$, respectively. The overall Kappa Cohen coefficient of agreement varied between $0.349-0.638$ for EPE and between 0.507-0.668 for SVI.

Conclusions. Our results showed that $1.5 \mathrm{~T} \mathrm{mp-MRI} \mathrm{is} \mathrm{a} \mathrm{reliable} \mathrm{method} \mathrm{for} \mathrm{local}$ staging of prostate cancer, with good diagnostic performance in detecting EPE and SVI. The overall interobserver agreement rates between readers with the same level of experience in prostate MRI ranged from fair to good in the evaluation of EPE and from moderate to good for the assessment of SVI.

Keywords: Magnetic Resonance Imaging, prostate cancer, staging

\section{Background and aim}

Prostate cancer extension at the

DOI: $10.15386 / \mathrm{mpr}-1390$

Manuscript received: 08.06.2019

Received in revised form: 28.10 .2019

Accepted: 18.11.2019

Address for correspondence: cristianpopita@gmail.com

This work is licensed under a Creative Commons Attribution-NonCommercialNoDerivatives 4.0 International License time of diagnosis is a key factor that influences the patient's prognosis and is essential for the selection of appropriate therapy $[1,2]$. The management of patients with prostate cancer is, traditionally, based on a combination of parameters, including clinical stage - through digital rectal examination, values of prostate specific antigen (PSA) and histological grade of tumor (Gleason score) - obtained from transrectal ultrasound (TRUS) guided biopsy. Although the above-mentioned techniques can detect prostate neoplasm and determine its aggressiveness, they often lead to understaging and their accuracy in the detection of locally advanced disease is limited $[3,4]$. Thus, additional methods for predicting local staging, such as imaging techniques, are investigated for their added value in the therapeutic decision $[5,6]$.

Multiparametric-Magnetic 
Resonance Imaging (mp-MRI), consisting of a combination of anatomic sequences - T2-weighted imaging (T2WI) and functional techniques - diffusion-weighted imaging (DWI) with apparent-diffusion coefficient (ADC), dynamic contrast enhanced (DCE-MRI) - has been shown to improve the localization and staging of prostate neoplasms, mainly the identification of extraprostatic extension (EPE) and seminal vesicle invasion (SVI) [7-10]. An increased number of studies have investigated the diagnostic performance of mp-MRI in local staging of prostate cancer, using different magnetic field strengths, endorectal coil (ERC) and various combination of anatomic and functional MRI sequences. The accuracy of mp-MRI has been shown to be highly variable, despite the involvement of highly experienced radiologists and investigations originating from large referral centers reported sensitivities (Se) and specificities (Sp) ranging between $43-90 \%$ and $74-94 \%$ for EPE and between 34.9$100 \%$ and $95-99 \%$ for SVI [3,11-17].

The aim of the study presented here was to assess the interobserver agreement and diagnostic performance of mp-MRI in the local staging of prostate cancer, using the histopathologic findings at prostatectomy as reference standard.

\section{Material and methods \\ Study design and patients}

This was a prospective, observational, single-center study performed in Cluj-Napoca, between October 2012 and October 2016. Consecutive men patients referred for prostate mp-MRI, either before or after a systematic 12 core TRUS-guided prostate biopsy, were invited to participate. For each patient, mp-MRI examination was read by three independent radiologists (Readers 1,2 and 3 ) with 3 years of experience in prostate MRI, who were blinded to each other. The radiologists were informed about the patient's PSA history and clinical data. In the subset of patients with mp-MRI performed after TRUS-guided biopsy, the radiologists were aware of the histopathological results. Following mp-MRI, additional data was collected, and patients were retained for the analysis if they had histologically proved prostate cancer at biopsy (performed either before or after mp-MRI) and radical prostatectomy was planned after mp-MRI. Exclusion criteria included any treatment for prostate cancer before radical prostatectomy and lack of subsequent radical prostatectomy.

This study was approved by the local ethics committee, and written informed consent was obtained from all patients prior to any study procedures. The study was carried out in agreement with The Code of Ethics of the World Medical Association (Helsinki Declaration) for experiments involving human subjects and with the Helsinki Declaration of 1975, as revised in 2000.

\section{MRI technique}

Mp-MRI examinations were performed using a 1.5T MRI unit (Magnetom Avanto, Siemens Healthcare, Erlangen, Germany), with a 6-element body matrix coil. An endorectal coil (ERC; Medrad Bayer Medical Care Inc., Indianola, PA, USA) was used in combination with the body matrix coil in a subset of patients (Table I). The ERC was inflated with $40-60 \mathrm{ml}$ of air for a good fit. No prior bowel preparation was used. For DCE, a gadolinium-based contrast agent was administered intravenous as bolus, at a dose of 0.1 $\mathrm{mmol} / \mathrm{kg}$, followed by a $20 \mathrm{ml}$ saline flush. Patients were examined in feet-first-supine position using the same MRI protocol, derived from the staging protocol provided by ESUR guidelines in 2012 [18] (Table I). Similar locations were used for axial T2WI, DWI and DCE.

\section{Image interpretation}

For all patients, the image interpretation was done using Syngo (VB17) software, commercially available applications and OsiriX MD viewer. Mp-MRI findings were reported as "positive" for EPE and/or SVI based on definition criteria and "negative" if prostate cancer was considered organ-confined. In the subset of patients with prior TRUS-guided biopsy, hypointense areas on T2WI with hyperintense signal in pre-contrast T1WI were associated with hemorrhage in the prostate or seminal vesicles. The reference standard for EPE and SVI was the histopathological report after radical prostatectomy.

Table I. Multiparametric MRI acquisition protocol.

\begin{tabular}{|c|c|c|c|c|c|c|c|}
\hline Magnetom Avanto 1.5-T & $\begin{array}{l}\text { Axial } \\
\text { T2WI }\end{array}$ & $\begin{array}{l}\text { Sagital } \\
\text { T2WI }\end{array}$ & $\begin{array}{c}\text { Coronal } \\
\text { T2WI }\end{array}$ & Axial DWI & $\begin{array}{c}\text { Axial T2 } \\
\text { fat-sat }\end{array}$ & $\begin{array}{c}\text { Coronal } \\
\text { T1WI }\end{array}$ & Axial DCE \\
\hline Sequence & TSE & TSE & TSE & EPI DWI & TSE & TSE & 2D FLASH \\
\hline TR (ms) & 4490 & 4100 & 3000 & 6500 & 12770 & 706 & 4.9 \\
\hline $\mathrm{TE}(\mathrm{ms})$ & 92 & 92 & 92 & 98 & 75 & 12 & 2.4 \\
\hline $\mathrm{FOV}\left(\mathrm{mm}^{2}\right)$ & 230 & 240 & 200 & 360 & 350 & 400 & 410 \\
\hline Flip angle $\left(^{\circ}\right)$ & 150 & 150 & 150 & - & 150 & 165 & 9 \\
\hline Matrix & $224 \times 320$ & $224 \times 320$ & $224 \times 320$ & $143 \times 192$ & $157 \times 256$ & $174 \times 256$ & $143 \times 320$ \\
\hline B-values & - & - & - & $50,500,800,1000,1200$ & - & - & - \\
\hline Slice thickness (mm), no gaps & 3 & 3 & 3 & 3 & 3 & 3.5 & 2.5 \\
\hline
\end{tabular}

$\mathrm{TR}=$ repetition time; $\mathrm{TE}=$ echo time $; \mathrm{FOV}=$ field of view; $\mathrm{TSE}=$ turbo spin echo $\mathrm{EPI}=$ echo planar imaging; FLASH $=$ fast low angle shot. 


\section{Definition of EPE}

EPE was evaluated with mp-MRI and correlated with histopathological report after radical prostatectomy. According to ESUR guidelines and Prostate ImagingReporting and Data System (PI-RADS) version 2 [18,19], we used direct and indirect imaging signs for assessing EPE: broad capsular contact $>10 \mathrm{~mm}$, bulging prostatic contour, irregular or spiculated margin, invasion of the neurovascular bundles, obliteration of the rectoprostatic angle and breach of the capsule with direct extracapsular tumor extension. The imaging findings were considered "true positive" if the histopathological results at prostatectomy confirmed EPE and "true negative" if the pathologist found no extracapsular extension.

\section{Definition of SVI}

The accuracy of mp-MRI in predicting the SVI was evaluated considering different routes of seminal vesicle involvement: focal or diffuse areas of low signal intensity on T2WI and/or abnormal contrast enhancement within or along the seminal vesicle, restricted diffusion, obliteration of the vesicoprostatic angle and the evidence of direct tumor extension into and around the seminal vesicle, as stated in the above-mentioned guidelines $[18,19)$. The mp-MRI findings were considered "true positive" if the pathological report after radical prostatectomy confirmed SVI and "true negative" if no SVI was noted.

\section{Histopathological analysis}

All enrolled patients underwent a radical prostatectomy and histopathological analysis was performed on whole-mount prostatectomy specimens. After excision, specimens were measured, coated with India ink and fixed in $10 \%$ buffered formaldehyde solution for 24 hours. Transverse whole-mount sections were made at 4 milimeter intervals in a perpendicular plane to the prostatic urethra. All sections were routinely embedded in paraffin. Tissue sections were cut at $4 \mu \mathrm{m}$ and stained with hematoxylineosin. Slides were examined by a pathologist with 19 years of experience in prostate pathology, who was blinded to the mp-MRI findings. The pathologist assessed the tumor location, Gleason score, EPE and SVI. All prostatectomy specimens were assigned to a stage according to the 2009 TNM classification [20].

\section{Statistical analyses}

MedCalc 10.3.0.0 (MedCalc Software bvba, Ostend, Belgium) and IBM SPSS Statistics version 20 (SPSS Inc., Chicago, IL, USA) were used for data analysis. Data was summarized using descriptive statistics. For all three readers were assessed, by Receiver Operating Characteristics, area under the curve (AUC), Se, Sp, positive predictive value (PPV), and negative predictive value (NPV) of mp-MRI in identifying EPE and SVI, overall and by timing of mp-MRI before or after TRUS-guided biopsy. Accuracy rates were calculated as (number of true negative cases + number of true positive cases)/number of all cases assessed. Cohen's kappa coefficient was used to assess interobserver agreement. A p $<0.05$ was considered statistically significant.

\section{Results}

The 195 consecutive patients with clinically suspected or biopsy confirmed prostate cancer were assessed between October 2012 and October 2016 by mp-MRI, prior to radical prostatectomy. After excluding those who did not fulfill the inclusion criteria or presented exclusion criteria, 50 patients were enrolled and included in the study. Of these, 36 patients had a biopsy proved prostate cancer before performing the mp-MRI and in 14 patients the TRUSguided biopsy was performed after mp-MRI. ERC was used in $23(46 \%)$ patients: 4 biopsy-naïve men and 19 patients with biopsy confirmed prostate cancer prior to mp-MRI. The median PSA taken from blood samples was $11.9 \mathrm{ng} / \mathrm{ml}$, with values from $4.02 \mathrm{ng} / \mathrm{ml}$ to $64 \mathrm{ng} / \mathrm{ml}$ (Table II).

\section{Accuracy of mp-MRI in detecting EPE and SVI}

In the whole population enrolled, EPE was identified after radical prostatectomy in 17 cases and SVI in 7 cases. The number of positive and negative EPE and SVI cases in the whole sample, as well as according to the timing of TRUS-guided biopsy and ERC use are shown in Figures 1 and 2 .

Table II. Characteristics of patients enrolled.

$\begin{array}{lc}\text { Parameters } & \text { Data N=50 } \\ \text { Age (years), mean } \pm \text { SD } & 64.4 \pm 7.2 \\ \text { PSA level (ng/ml), median (Q1; Q3) } & 11.9(7.6 ; 20.7) \\ \text { Gleason score biopsy, median (Q1; Q3) } & 7.0(6.0 ; 7.0) \\ \text { Gleason score prostatectomy, median (Q1; Q3) } & 7.0(7.0 ; 7.0) \\ \text { mp-MRI with ERC, n (\%) } & 23(46.0 \%) \\ \text { Positive TRUS-guided biopsy before mp-MRI, n (\%) } & 36(72.0 \%) \\ \text { Time prostate biopsy-to-MRI (weeks), median (Q1; Q3) } & 6.0(5.0 ; 8.5) \\ \text { Time MRI-to-prostatectomy (weeks), median (Q1; Q3) } & 4.5(2.0 ; 8.5) \\ \text { Hemorrhagic findings in mp-MRI performed after biopsy, n (\%) } & 23(63.9 \%)\end{array}$

$\mathrm{SD}=$ standard deviation; Q1 = quartile 1; Q3 = quartile 3; n (\%) = number (percentage) of patients; PSA = prostate-specific antigen; $\mathrm{ERC}=$ endorectal coil; $\mathrm{mp}-\mathrm{MRI}=$ multiparametric MRI. 


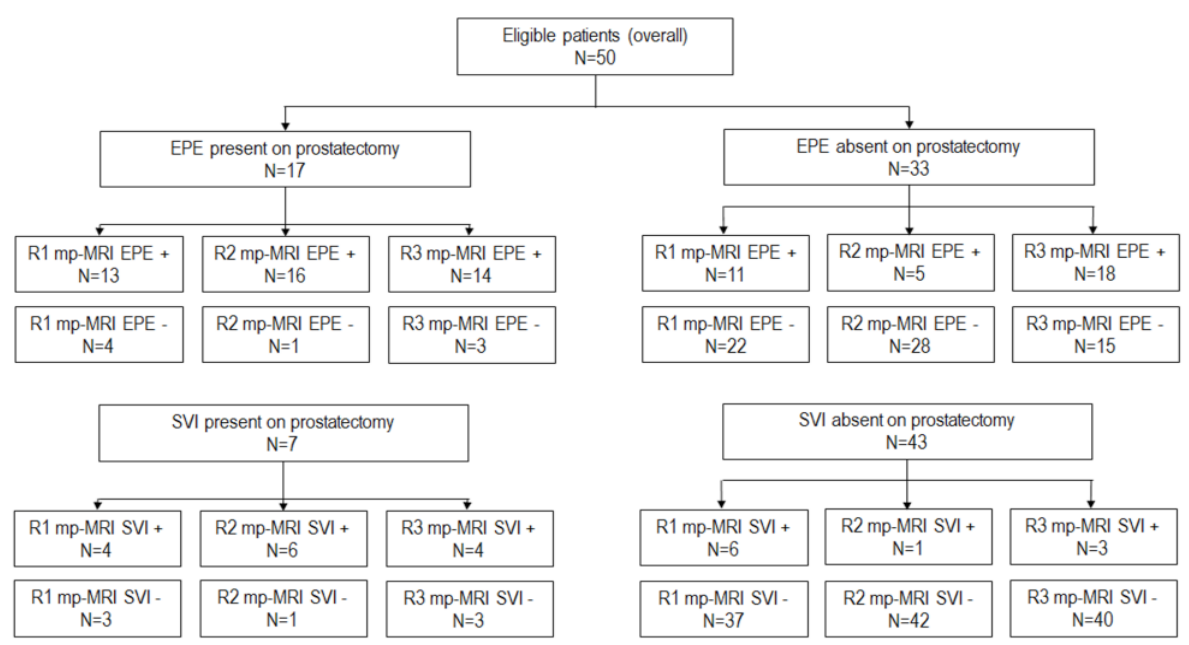

B

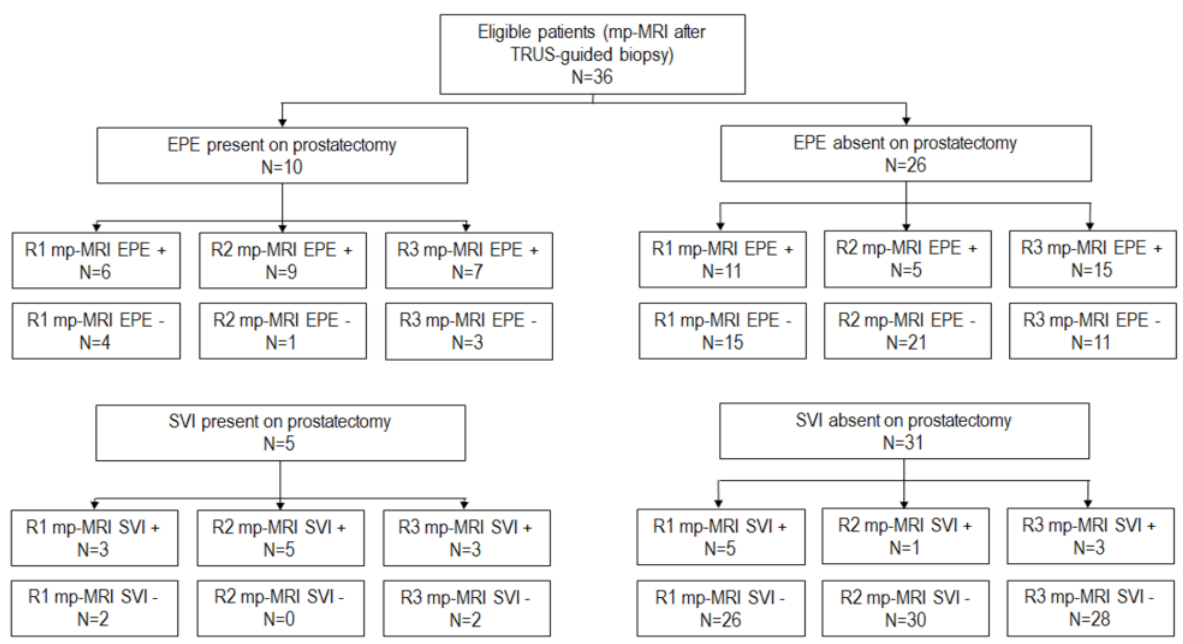

c

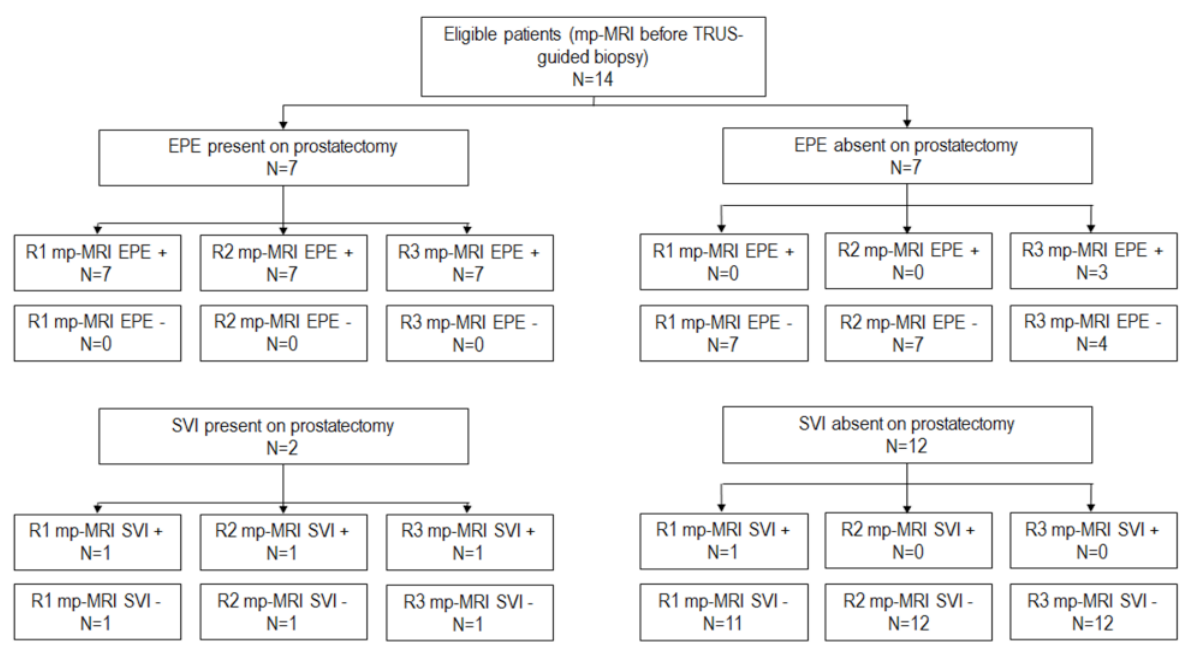

Figure 1. STARD diagram for the whole population enrolled overall (panel A) and according to mp-MRI timing (panels B and C). The histopathological finding at radical prostatectomy was used as reference test and mp-MRI the index test.

$\mathrm{mp}-\mathrm{MRI}=$ multiparametric MRI; EPE $=$ extraprostatic tumor extension; $\mathrm{SVI}=$ seminal vesicle invasion; $\mathrm{R} 1=$ Reader $1 ; \mathrm{R} 2=$ Reader 2 ; $\mathrm{R} 3=$ Reader $3 ;+=$ positive at index test $;-=$ negative at index test. 
A

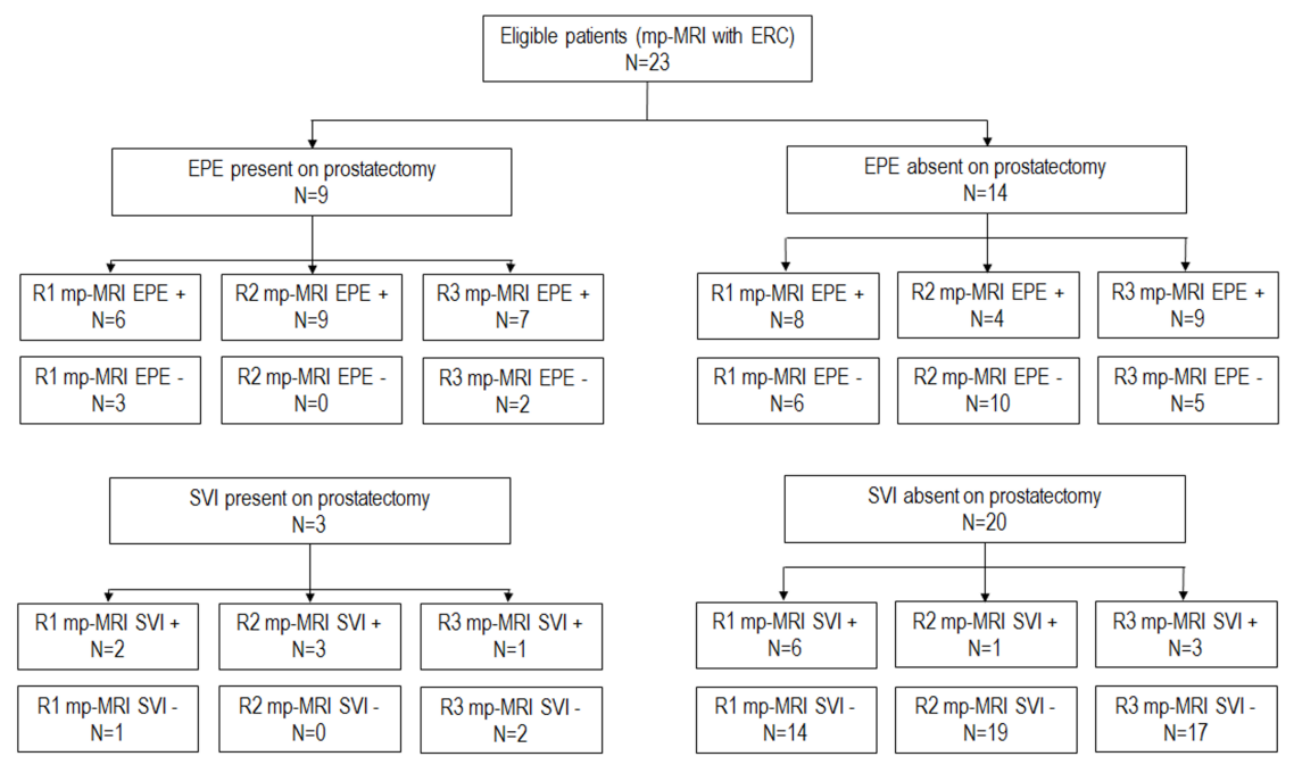

B

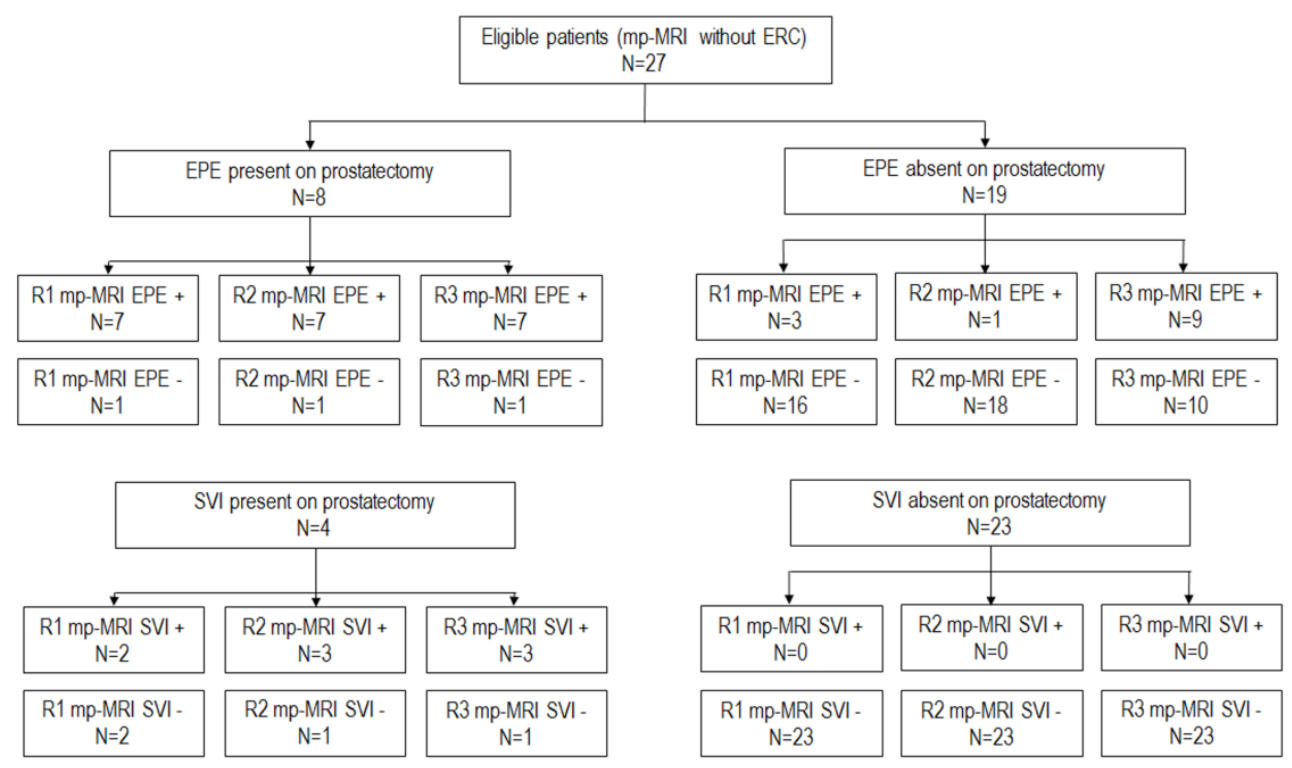

Figure 2. STARD diagram for the population enrolled according to the use of endorectal coil - panel A for patients without ERC and panel B for patients with ERC. The histopathological finding at radical prostatectomy was used as reference test and mp-MRI as the index test.

mp-MRI = multiparametric MRI; ERC = endorectal coil; $\mathrm{EPE}=$ extraprostatic tumor extension; $\mathrm{SVI}=$ seminal vesicle invasion; $\mathrm{R} 1=$ Reader $1 ; \mathrm{R} 2=$ Reader 2 ; R3 = Reader $3 ;+=$ positive at index test; - = negative at index test.

For EPE Se ranged between $76.5 \%$ in reader 1 and $94.1 \%$ in reader $2, \mathrm{Sp}$ ranged between $45.5 \%$ in reader 3 and $84.9 \%$ in reader 2 and accuracy rates ranged between $58-88 \%$ (Table III).
For SVI Se ranged between 57.1-85.7\%, Sp between $86.1-97.7 \%$ and accuracy rates between $82-96 \%$ (Table IV). 
Table III. Diagnostic performance of mp-MRI to correctly identify EPE (prostatectomy specimens used as reference standard).

\begin{tabular}{|c|c|c|c|c|c|c|}
\hline & $\begin{array}{l}\text { Sensitivity, } \\
\%(95 \% \text { CI })\end{array}$ & $\begin{array}{l}\text { Specificity, } \\
\%(95 \% \mathrm{CI})\end{array}$ & $\begin{array}{c}\text { PPV, } \\
\%(95 \% \mathrm{CI})\end{array}$ & $\begin{array}{c}\text { NPV, } \\
\%(95 \% C I)\end{array}$ & $\begin{array}{c}\mathrm{AUC}^{\mathrm{a}} \\
(95 \% \mathrm{CI})\end{array}$ & $\begin{array}{c}\text { Accuracy } \\
\text { rate, } \%\end{array}$ \\
\hline \multicolumn{7}{|l|}{ Overall } \\
\hline Reader 1 & $\begin{array}{c}76.5 \\
(50.1 ; 93.2)\end{array}$ & $\begin{array}{c}66.7 \\
(48.2 ; 82.0)\end{array}$ & $\begin{array}{c}54.2 \\
(40.5 ; 67.2)\end{array}$ & $\begin{array}{c}84.6 \\
(69.3 ; 93.1)\end{array}$ & $\begin{array}{c}0.716 \\
(0.571 ; 0.834)^{\mathrm{b}}\end{array}$ & 70.0 \\
\hline Reader 2 & $\begin{array}{c}94.1 \\
(71.3 ; 99.9)\end{array}$ & $\begin{array}{c}84.9 \\
(68.1 ; 94.9)\end{array}$ & $\begin{array}{c}76.2 \\
(58.6 ; 87.9)\end{array}$ & $\begin{array}{c}96.6 \\
(80.6 ; 99.5)\end{array}$ & $\begin{array}{c}0.895 \\
(0.775 ; 0.964)^{b}\end{array}$ & 88.0 \\
\hline Reader 3 & $\begin{array}{c}82.4 \\
(56.6 ; 96.2)\end{array}$ & $\begin{array}{c}45.5 \\
(28.1 ; 63.6)\end{array}$ & $\begin{array}{c}43.8 \\
(34.7 ; 53.2)\end{array}$ & $\begin{array}{c}83.3 \\
(62.6 ; 93.7)\end{array}$ & $\begin{array}{c}0.639 \\
(0.491 ; 0.770)^{\mathrm{b}}\end{array}$ & 58.0 \\
\hline \multicolumn{7}{|c|}{ mp-MRI performed after positive TRUS-guided prostate biopsy } \\
\hline Reader 1 & $\begin{array}{c}60.0 \\
(26.2 ; 87.8)\end{array}$ & $\begin{array}{c}57.7 \\
(36.9 ; 76.6)\end{array}$ & $\begin{array}{c}35.3 \\
(21.7 ; 51.8)\end{array}$ & $\begin{array}{c}78.9 \\
(62.1 ; 89.6)\end{array}$ & $\begin{array}{c}0.588 \\
(0.413 ; 0.749)^{\mathrm{c}}\end{array}$ & 58.3 \\
\hline Reader 2 & $\begin{array}{c}90.0 \\
(55.5 ; 99.7)\end{array}$ & $\begin{array}{c}80.8 \\
(60.6 ; 93.4)\end{array}$ & $\begin{array}{c}64.3 \\
(44.4 ; 80.3)\end{array}$ & $\begin{array}{c}95.5 \\
(76.4 ; 99.3)\end{array}$ & $\begin{array}{c}0.854 \\
(0.696 ; 0.949)^{\mathrm{c}}\end{array}$ & 83.3 \\
\hline Reader 3 & $\begin{array}{c}70.0 \\
(34.8 ; 93.3)\end{array}$ & $\begin{array}{c}42.3 \\
(23.4 ; 63.1)\end{array}$ & $\begin{array}{c}31.8 \\
(21.7 ; 44.0)\end{array}$ & $\begin{array}{c}78.6 \\
(56.3 ; 91.3)\end{array}$ & $\begin{array}{c}0.562 \\
(0.387 ; 0.726)^{\mathrm{c}}\end{array}$ & 50.0 \\
\hline \multicolumn{7}{|c|}{ mp-MRI performed before positive TRUS-guided prostate biopsy } \\
\hline Reader 1 & $\begin{array}{c}100.0 \\
(59.0 ; 100.0)\end{array}$ & $\begin{array}{c}100.0 \\
(59.0 ; 100.0)\end{array}$ & 100.0 & 100.0 & $\begin{array}{c}1.000 \\
(0.768 ; 1.000)^{\mathrm{d}}\end{array}$ & 100.0 \\
\hline Reader 2 & $\begin{array}{c}100.0 \\
(59.0 ; 100.0)\end{array}$ & $\begin{array}{c}100.0 \\
(59.0 ; 100.0)\end{array}$ & 100.0 & 100.0 & $\begin{array}{c}1.000 \\
(0.768 ; 1.000)^{\mathrm{d}}\end{array}$ & 100.0 \\
\hline Reader 3 & $\begin{array}{c}100.0 \\
(59.0 ; 100.0)\end{array}$ & $\begin{array}{c}57.14 \\
(18.4 ; 90.1)\end{array}$ & $\begin{array}{c}70.0 \\
(49.8 ; 84.6)\end{array}$ & 100.0 & $\begin{array}{c}0.786 \\
(0.492 ; 0.953)^{\mathrm{d}}\end{array}$ & 78.5 \\
\hline \multicolumn{7}{|c|}{ mp-MRI with ERC } \\
\hline Reader 1 & $\begin{array}{c}66.7 \\
(29.9 ; 92.5)\end{array}$ & $\begin{array}{c}42.9 \\
(17.7 ; 71.1)\end{array}$ & $\begin{array}{c}42.9 \\
(28.2 ; 58.9)\end{array}$ & $\begin{array}{c}66.7 \\
(39.9 ; 85.8)\end{array}$ & $\begin{array}{c}0.548 \\
(0.329 ; 0.754)^{\mathrm{e}}\end{array}$ & 52.2 \\
\hline Reader 2 & $\begin{array}{c}100.0 \\
(66.4 ; 100.0)\end{array}$ & $\begin{array}{c}71.4 \\
(41.9 ; 91.6)\end{array}$ & $\begin{array}{c}69.2 \\
(49.6 ; 83.7)\end{array}$ & 100.0 & $\begin{array}{c}0.857 \\
(0.649 ; 0.966)^{\mathrm{e}}\end{array}$ & 82.6 \\
\hline Reader 3 & $\begin{array}{c}77.8 \\
(40.0 ; 97.2)\end{array}$ & $\begin{array}{c}35.7 \\
(12.8 ; 64.9)\end{array}$ & $\begin{array}{c}43.8 \\
(31.5 ; 56.8)\end{array}$ & $\begin{array}{c}71.4 \\
(37.9 ; 91.1)\end{array}$ & $\begin{array}{c}0.567 \\
(0.347 ; 0.770)^{\mathrm{e}}\end{array}$ & 52.2 \\
\hline \multicolumn{7}{|c|}{ mp-MRI without ERC } \\
\hline Reader 1 & $\begin{array}{c}87.5 \\
(47.3 ; 99.7)\end{array}$ & $\begin{array}{c}84.2 \\
(60.4 ; 96.6)\end{array}$ & $\begin{array}{c}70.0 \\
(44.4 ; 87.2)\end{array}$ & $\begin{array}{c}94.1 \\
(71.7 ; 99.0)\end{array}$ & $\begin{array}{c}0.859 \\
(0.671 ; 0.962)^{\mathrm{f}}\end{array}$ & 85.2 \\
\hline Reader 2 & $\begin{array}{c}85.7 \\
(47.3 ; 99.7)\end{array}$ & $\begin{array}{c}94.7 \\
(74.0 ; 99.9)\end{array}$ & $\begin{array}{c}87.5 \\
(50.5 ; 98.0)\end{array}$ & $\begin{array}{c}94.7 \\
(74.2 ; 99.1)\end{array}$ & $\begin{array}{c}0.911 \\
(0.737 ; 0.986)^{\mathrm{f}}\end{array}$ & 92.6 \\
\hline Reader 3 & $\begin{array}{c}87.5 \\
(47.3 ; 99.7)\end{array}$ & $\begin{array}{c}52.6 \\
(28.9 ; 75.6)\end{array}$ & $\begin{array}{c}43.8 \\
(31.1 ; 57.2)\end{array}$ & $\begin{array}{c}90.9 \\
(60.4 ; 98.5)\end{array}$ & $\begin{array}{c}0.701 \\
(0495 ; 0.860)^{\mathrm{f}}\end{array}$ & 63.0 \\
\hline
\end{tabular}

mp-MRI = multiparametric MRI; TRUS = transrectal ultrasound; ERC = endorectal coil; PPV = positive predictive value; NPV = negative predictive value; $\mathrm{CI}=$ confidence interval; $\mathrm{AUC}=$ area under the receiver operating curve

${ }^{a}$ p-values $<0.05$ for AUCs computed in the whole sample, for reader 2 in group with positive TRUS-guided biopsy performed before mp-MRI, for all readers in the group with positive TRUS-guided biopsy after mp-MRI, for reader 2 in group with ERC and for readers 1 and 2 in group without ERC

${ }^{b} p$-values for pairwise comparison between AUC for the 3 readers in the overall population: 0.001 for the comparison between reader 1 and reader 2; 0.259 for the comparison between reader 1 and reader 3;0.001 for the comparison between reader 2 and reader 3

cp-values for pairwise comparison between AUC for the 3 readers in the group with positive TRUS-guided biopsy performed before mp-MRI: 0.007 for the comparison between reader 1 and reader 2; 0.756 for the comparison between reader 1 and reader 3; 0.006 for the comparison between reader 2 and reader 3

${ }^{\mathrm{d}} \mathrm{p}$-values for pairwise comparison between AUC for the 3 readers in the group with positive TRUS-guided biopsy performed after mpMRI: 1.000 for the comparison between readers 1 and reader 2; 0.102 for the comparison between reader 1 and reader 3; 0.102 for the comparison between reader 2 and reader 3

ep-values for pairwise comparison between AUC for the 3 readers in group with ERC: 0.017 for the comparison between reader 1 and reader 2; 0.850 for the comparison between reader 1 and reader 3; 0.043 for the comparison between reader 2 and reader 3 ${ }_{\mathrm{f}}^{\mathrm{p}}$-values for pairwise comparison between AUC for the 3 readers in group without ERC: 0.394 for the comparison between readers 1 and reader 2; 0.043 for the comparison between reader 1 and reader 3; 0.017 for the comparison between reader 2 and reader 3. 
Table IV. Diagnostic performance of mp-MRI to correctly identify SVI (prostatectomy specimens used as reference standard).

\begin{tabular}{|c|c|c|c|c|c|c|}
\hline & $\begin{array}{l}\text { Sensitivity, } \\
\%(95 \% \mathrm{CI})\end{array}$ & $\begin{array}{l}\text { Specificity, } \\
\%(95 \% \text { CI })\end{array}$ & $\begin{array}{c}\text { PPV, } \\
\%(95 \% \text { CI })\end{array}$ & $\begin{array}{c}\text { NPV, } \\
\%(95 \% \mathrm{CI})\end{array}$ & $\begin{array}{c}\mathrm{AUC}^{\mathrm{a}} \\
(95 \% \mathrm{CI})\end{array}$ & $\begin{array}{c}\text { Accuracy } \\
\text { rate, } \%\end{array}$ \\
\hline \multicolumn{7}{|l|}{ Overall } \\
\hline Reader 1 & $\begin{array}{c}57.1 \\
(18.4 ; 90.1)\end{array}$ & $\begin{array}{c}86.1 \\
(72.1 ; 94.7)\end{array}$ & $\begin{array}{c}40.0 \\
(20.0 ; 64.0)\end{array}$ & $\begin{array}{c}92.5 \\
(83.9 ; 96.7)\end{array}$ & $\begin{array}{c}0.716 \\
(0.571 ; 0.834)^{b}\end{array}$ & 82.0 \\
\hline Reader 2 & $\begin{array}{c}85.7 \\
(42.1 ; 99.6)\end{array}$ & $\begin{array}{c}97.7 \\
(87.7 ; 99.1)\end{array}$ & $\begin{array}{c}85.7 \\
(45.8 ; 97.7)\end{array}$ & $\begin{array}{c}97.7 \\
(87.2 ; 99.6)\end{array}$ & $\begin{array}{c}0.917 \\
(0.804 ; 0.976)^{b}\end{array}$ & 96.0 \\
\hline Reader 3 & $\begin{array}{c}57.1 \\
(18.4 ; 90.1)\end{array}$ & $\begin{array}{c}93.0 \\
(80.9 ; 98.5)\end{array}$ & $\begin{array}{c}57.1 \\
(27.3 ; 82.5)\end{array}$ & $\begin{array}{c}93.0 \\
(85.0 ; 96.9)\end{array}$ & $\begin{array}{c}0.751 \\
(0.608 ; 0.862)^{b}\end{array}$ & 88.0 \\
\hline \multicolumn{7}{|c|}{ mp-MRI performed after positive TRUS-guided prostate biopsy } \\
\hline Reader 1 & $\begin{array}{c}60.0 \\
(14.7 ; 94.7)\end{array}$ & $\begin{array}{c}83.9 \\
(66.3 ; 94.5)\end{array}$ & $\begin{array}{c}37.5 \\
(17.0 ; 63.8)\end{array}$ & $\begin{array}{c}92.9 \\
(81.5 ; 97.5)\end{array}$ & $\begin{array}{c}0.719 \\
(0.545 ; 0.856)^{\mathrm{c}}\end{array}$ & 80.5 \\
\hline Reader 2 & $\begin{array}{c}100.0 \\
(47.8 ; 100.0)\end{array}$ & $\begin{array}{c}96.8 \\
(83.3 ; 99.9)\end{array}$ & $\begin{array}{c}83.3 \\
(42.1 ; 97.2)\end{array}$ & 100.0 & $\begin{array}{c}0.984 \\
(0.874 ; 1.000)^{\mathrm{c}}\end{array}$ & 97.2 \\
\hline Reader 3 & $\begin{array}{c}60.0 \\
(14.7 ; 94.7)\end{array}$ & $\begin{array}{c}90.3 \\
(74.2 ; 98.0)\end{array}$ & $\begin{array}{c}50.0 \\
(21.6 ; 78.4)\end{array}$ & $\begin{array}{c}93.3 \\
(82.6 ; 97.6)\end{array}$ & $\begin{array}{c}0.752 \\
(0.580 ; 0.880)^{\mathrm{c}}\end{array}$ & 86.1 \\
\hline \multicolumn{7}{|c|}{ mp-MRI performed before positive TRUS-guided prostate biopsy } \\
\hline Reader 1 & $\begin{array}{c}50.0 \\
(1.3 ; 98.7)\end{array}$ & $\begin{array}{c}91.7 \\
(61.5 ; 99.8)\end{array}$ & $\begin{array}{c}50.0 \\
(8.8 ; 91.2)\end{array}$ & $\begin{array}{c}91.7 \\
(73.1 ; 97.8)\end{array}$ & $\begin{array}{c}0.708 \\
(0.413 ; 0.913)^{d}\end{array}$ & 85.7 \\
\hline Reader 2 & $\begin{array}{c}50.0 \\
(1.3 ; 98.7)\end{array}$ & $\begin{array}{c}100.0 \\
(73.5 ; 100.0)\end{array}$ & 100.0 & $\begin{array}{c}92.3 \\
(75.0 ; 98.0)\end{array}$ & $\begin{array}{c}0.750 \\
(0.455 ; 0.936)^{d}\end{array}$ & 92.8 \\
\hline Reader 3 & $\begin{array}{c}50.0 \\
(1.3 ; 98.7)\end{array}$ & $\begin{array}{c}100.0 \\
(73.5 ; 100.0)\end{array}$ & 100.0 & $\begin{array}{c}92.3 \\
(75.0 ; 98.0)\end{array}$ & $\begin{array}{c}0.750 \\
(0.455 ; 0.936)^{d}\end{array}$ & 92.8 \\
\hline \multicolumn{7}{|c|}{ mp-MRI with ERC } \\
\hline Reader 1 & $\begin{array}{c}66.7 \\
(9.4 ; 99.2)\end{array}$ & $\begin{array}{c}70.0 \\
(45.7 ; 88.1)\end{array}$ & $\begin{array}{c}25.0 \\
(10.5 ; 48.6)\end{array}$ & $\begin{array}{c}93.3 \\
(73.4 ; 98.6)\end{array}$ & $\begin{array}{c}0.683 \\
(0.458 ; 0.859)^{\mathrm{e}}\end{array}$ & 69.6 \\
\hline Reader 2 & $\begin{array}{c}100.0 \\
(29.2 ; 100.0)\end{array}$ & $\begin{array}{c}95.0 \\
(75.1 ; 99.9)\end{array}$ & $\begin{array}{c}75.0 \\
(30.7 ; 95.3)\end{array}$ & 100.0 & $\begin{array}{c}0.975 \\
(0.809 ; 1.000)^{\mathrm{e}}\end{array}$ & 95.7 \\
\hline Reader 3 & $\begin{array}{c}33.3 \\
(0.8 ; 90.6)\end{array}$ & $\begin{array}{c}85.0 \\
(62.1 ; 96.8)\end{array}$ & $\begin{array}{c}25.0 \\
(4.7 ; 69.2)\end{array}$ & $\begin{array}{c}89.5 \\
(78.9 ; 95.1)\end{array}$ & $\begin{array}{c}0.592 \\
(0.369 ; 0.789)^{\mathrm{e}}\end{array}$ & 78.3 \\
\hline \multicolumn{7}{|c|}{ mp-MRI without ERC } \\
\hline Reader 1 & $\begin{array}{c}50.0 \\
(6.8 ; 93.2)\end{array}$ & $\begin{array}{c}100.0 \\
(85.2 ; 100.0)\end{array}$ & 100.0 & $\begin{array}{c}92.0 \\
(81.2 ; 96.9)\end{array}$ & $\begin{array}{c}0.750 \\
(0.547 ; 0.895)^{\mathrm{f}}\end{array}$ & 92.6 \\
\hline Reader 2 & $\begin{array}{c}75.0 \\
(19.4 ; 99.4)\end{array}$ & $\begin{array}{c}100.0 \\
(85.2 ; 100.0)\end{array}$ & 100.0 & $\begin{array}{c}95.8 \\
(80.8 ; 99.2)\end{array}$ & $\begin{array}{c}0.875 \\
(0.691 ; 0.970)^{\mathrm{f}}\end{array}$ & 96.3 \\
\hline Reader 3 & $\begin{array}{c}75.0 \\
(19.4 ; 99.4)\end{array}$ & $\begin{array}{c}100.0 \\
(85.2 ; 100.0)\end{array}$ & 100.0 & $\begin{array}{c}95.8 \\
(80.8 ; 99.2)\end{array}$ & $\begin{array}{c}0.875 \\
(0.691 ; 0.970)^{\mathrm{f}}\end{array}$ & 96.3 \\
\hline
\end{tabular}

mp-MRI = multiparametric MRI; TRUS = transrectal ultrasound; ERC = endorectal coil; PPV = positive predictive value; NPV = negative predictive value; $\mathrm{CI}=$ confidence interval; $\mathrm{AUC}=$ area under the receiver operating curve

${ }^{a}$ p-values $<0.05$ for AUCs computed in the whole sample and for reader 2 in group with positive TRUS-guided biopsy performed before mp-MRI and in groups with and without ERC and for reader 3 in group without ERC

${ }^{\mathrm{b}} \mathrm{p}$-values for pairwise comparison between AUC for the 3 readers in the overall population: 0.082 for the comparison between reader 1 and reader 2; 0.767 for the comparison between reader 1 and reader 3;0.128 for the comparison between reader 2 and reader 3

c p-values for pairwise comparison between AUC for the 3 readers in the group with positive TRUS-guided biopsy performed before mp-MRI: 0.052 for the comparison between reader 1 and reader 2; 0.829 for the comparison between reader 1 and reader 3; 0.086 for the comparison between reader 2 and reader 3

${ }^{\mathrm{d}} \mathrm{p}$-values for pairwise comparison between AUC for the 3 readers in the group with positive TRUS-guided biopsy performed after mpMRI: 0.865 for the comparison between Reader 1 and Reader 2; 0.865 for the comparison between Reader 1 and Reader 3; 1.000 for the comparison between Reader 2 and Reader 3

ep-values for pairwise comparison between AUC for the 3 readers in group with ERC: 0.086 for the comparison between reader 1 and reader $2 ; 0.605$ for the comparison between reader 1 and reader 3; 0.039 for the comparison between reader 2 and reader 3

${ }_{\mathrm{f}}^{\mathrm{p}}$-values for pairwise comparison between AUC for the 3 readers in group without ERC: 0.499 for the comparison between reader 1 and reader $2 ; 0.499$ for the comparison between reader 1 and reader $3 ; 1.000$ for the comparison between reader 2 and reader 3 . 
In the subseries of patients in which mp-MRI was performed before prostate biopsy (14 patients), for EPE, the $\mathrm{Se}, \mathrm{Sp}$ and accuracy rate were higher in all readers (Se $100 \%$, Sp ranged between $57.1-100 \%$ and accuracy rate from $78.5 \%$ to $100 \%$ ) than in the group examined after biopsy (Table III). An example of EPE is shown in Figure 3.

In the group with MRI performed before TRUSguided biopsy all readers had low Se $(50.0 \%)$ but excellent Sp $(91.7 \%$ and $100 \%)$ in detecting SVI. In the group with MRI performed after biopsy Se varied according to reader from $60 \%$ to $100 \%$ and accuracy rates ranged between $80.5-97.2 \%$ (Table IV).

In the group of patients examined without ERC, all readers had similar Se $(87.5 \%)$ in detecting EPE and Sp ranged between $52.6 \%$ and $94.7 \%$. In all readers, the accuracy rates were higher in the group examined without ERC compared to group with ERC (Table III). For SVI, in the group with ERC the Se, Sp and accuracy rates varied among readers. In the group without ERC all readers had excellent Sp (100\%) and very good accuracy rates (ranging between 92.6\% and 96.3\%; Table IV).

\section{Interobserver agreement}

The coefficient of agreement ranged between 0.349 and 0.638 for EPE detection and between 0.507 and 0.668 for SVI identification. For EPE readers agreed more frequently in the group with mp-MRI performed before prostate biopsy (coefficient of agreement between 0.571 and 1.000) and in the group without ERC (coefficient of agreement between 0.449 and 0.834 ). Concordance was most frequently divergent in the group with mp-MRI performed after biopsy (coefficient of agreement between 0.259 and 0.616 ) and in the group examined with ERC (coefficient of agreement between 0.175 and 0.620 ). Similar variation in agreement according to groups was observed for SVI. Readers agreed more frequently for the group in which the mp-MRI was performed before TRUS-guided biopsy (coefficient of agreement between 0.632 and 1.000) and the group without ERC (coefficient of agreement between 0.780 and 1.000; Table V).

A very good inter-reader agreement in a patient with prostate cancer and SVI is illustrated in Figure 4.
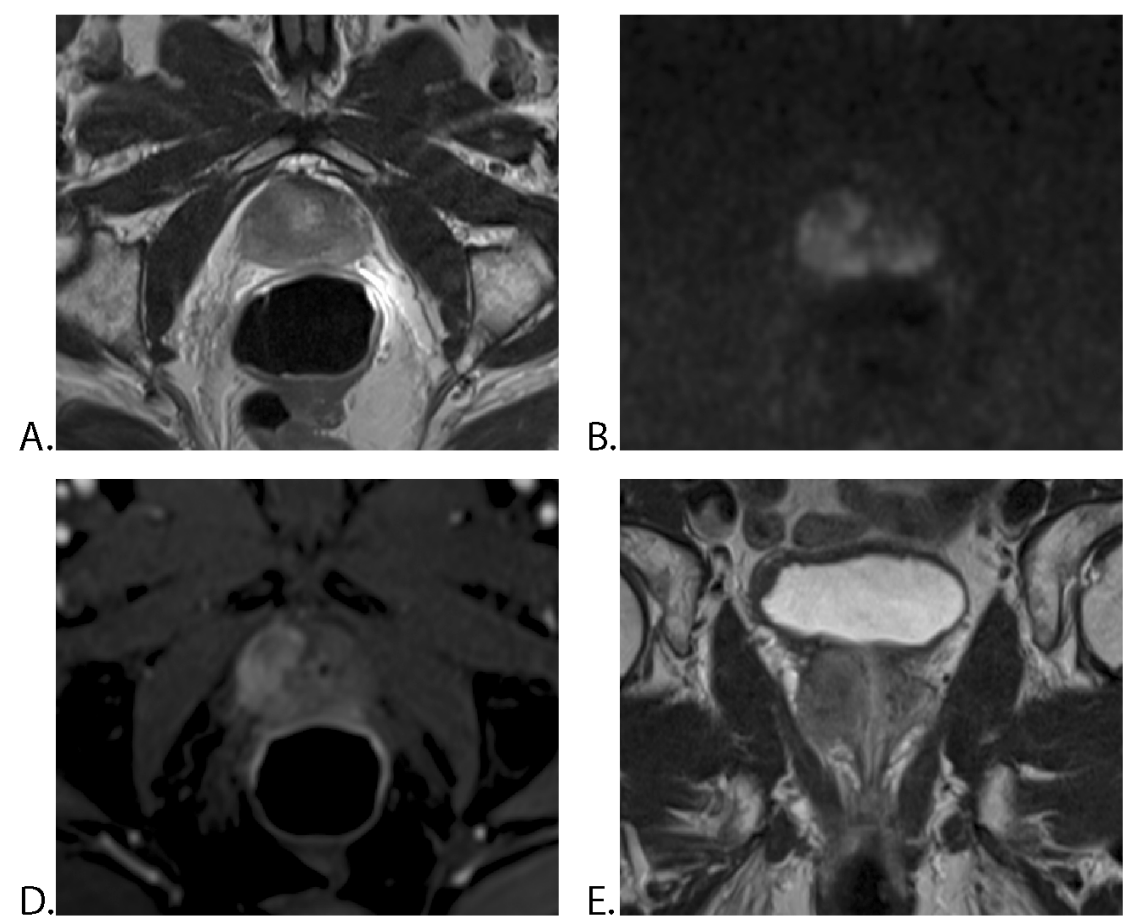
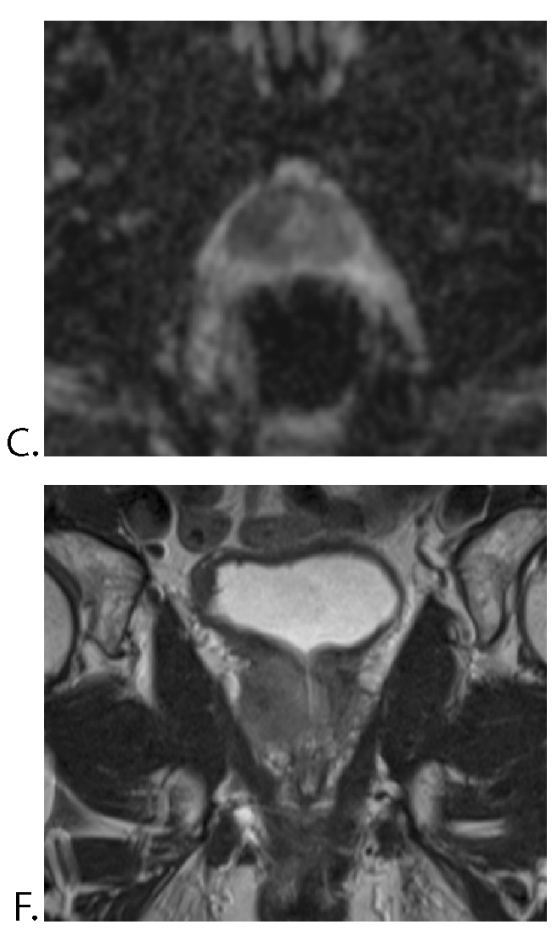

Figure 3. 63-year-old man with a PSA level of $14.32 \mathrm{ng} / \mathrm{ml}$ : mp-MRI with ERC, 7 weeks after positive prostate biopsy (Gleason score $3+3)$. A. Axial T2WI TSE, showing a homogeneous, hypointense mass in the peripheral zone of the right prostatic lobe. B. Axial DWI, C. ADC map and D. DCE-MRI showing mildly hyperintense signal on high b-value (b 1200) and markedly hypointense mass on ADC, with early enhancement. E. and F. Coronal T2WI TSE demonstrates broad capsular contact, bulging prostatic contour and breach of the capsule. All three readers reported a right prostatic mass with extraprostatic extension. The histopathological report after radical prostatectomy certified extracapsular extension (T3a).

$\mathrm{PSA}=$ prostate-specific antigen, $\mathrm{mp}-\mathrm{MRI}=$ multiparametric $\mathrm{MRI}, \mathrm{ERC}=$ endorectal coil, $\mathrm{TSE}=$ turbo spin echo. 
Table V. Mp-MRI interobserver agreement for the identification of the EPE and SVI in the overall population, according to the timing of TRUS-guided biopsy and the use of endorectal coil.

\begin{tabular}{|l|l} 
& Kappa Cohen coefficient of agreement (SE) \\
\hline EPE & Kas \\
\hline
\end{tabular}

Overall

Reader 1 - Reader 2

$0.638(0.109)$

Reader 1 - Reader 3

$0.604(0.106)$

Reader 2 - Reader 3

$0.349(0.117)$

mp-MRI performed after positive TRUS-guided prostate biopsy

Reader 1 - Reader 2

$0.494(0.144)$

Reader 1 - Reader 3

$0.616(0.125)$

Reader 2 - Reader 3

$0.259(0.143)$

mp-MRI performed before positive TRUS-guided prostate biopsy

Reader 1 - Reader 2

$1.000(0.000)$

Reader 1 - Reader 3

$0.571(0.198)$

Reader 2 - Reader 3

$0.571(0.198)$

mp-MRI with ERC

Reader 1 - Reader 2

$0.374(0.195)$

Reader 1 - Reader 3

$0.620(0.169)$

Reader 2 - Reader 3

$0.175(0.200)$

mp-MRI without ERC

Reader 1 - Reader 2

$0.834(0.111)$

Reader 1 - Reader 3

$0.576(0.138)$

Reader 2 - Reader 3

$0.449(0.136)$

\section{SVI}

Overall

Reader 1 - Reader 2

$0.507(0.160)$

Reader 1 - Reader 3

$0.648(0.143)$

Reader 2 - Reader 3

$0.668(0.154)$

mp-MRI performed after positive TRUS-guided prostate biopsy

Reader 1 - Reader 2

$0.471(0.183)$

Reader 1 - Reader 3

$0.647(0.160)$

Reader 2 - Reader 3

$0.600(0.181)$

mp-MRI performed before positive TRUS-guided prostate biopsy

Reader 1 - Reader 2

$0.632(0.330)$

Reader 1 - Reader 3

$0.632(0.330)$

Reader 2 - Reader 3

$1.000(0.000)$

mp-MRI with ERC

Reader 1 - Reader 2

$0.349(0.198)$

Reader 1 - Reader 3

$0.566(0.178)$

Reader 2 - Reader 3

$0.395(0.248)$

mp-MRI without ERC

Reader 1 - Reader 2

$0.780(0.210)$

Reader 1 - Reader 3

$0.780(0.210)$

Reader 2 - Reader 3

$1.000(0.000)$

$\mathrm{Mp}-\mathrm{MRI}=$ multiparametric MRI; EPE = extraprostatic tumor extension; SVI = seminal vesicle invasion; TRUS = transrectal ultrasound; $\mathrm{ERC}=$ endorectal coil $; \mathrm{SE}=$ standard error. 

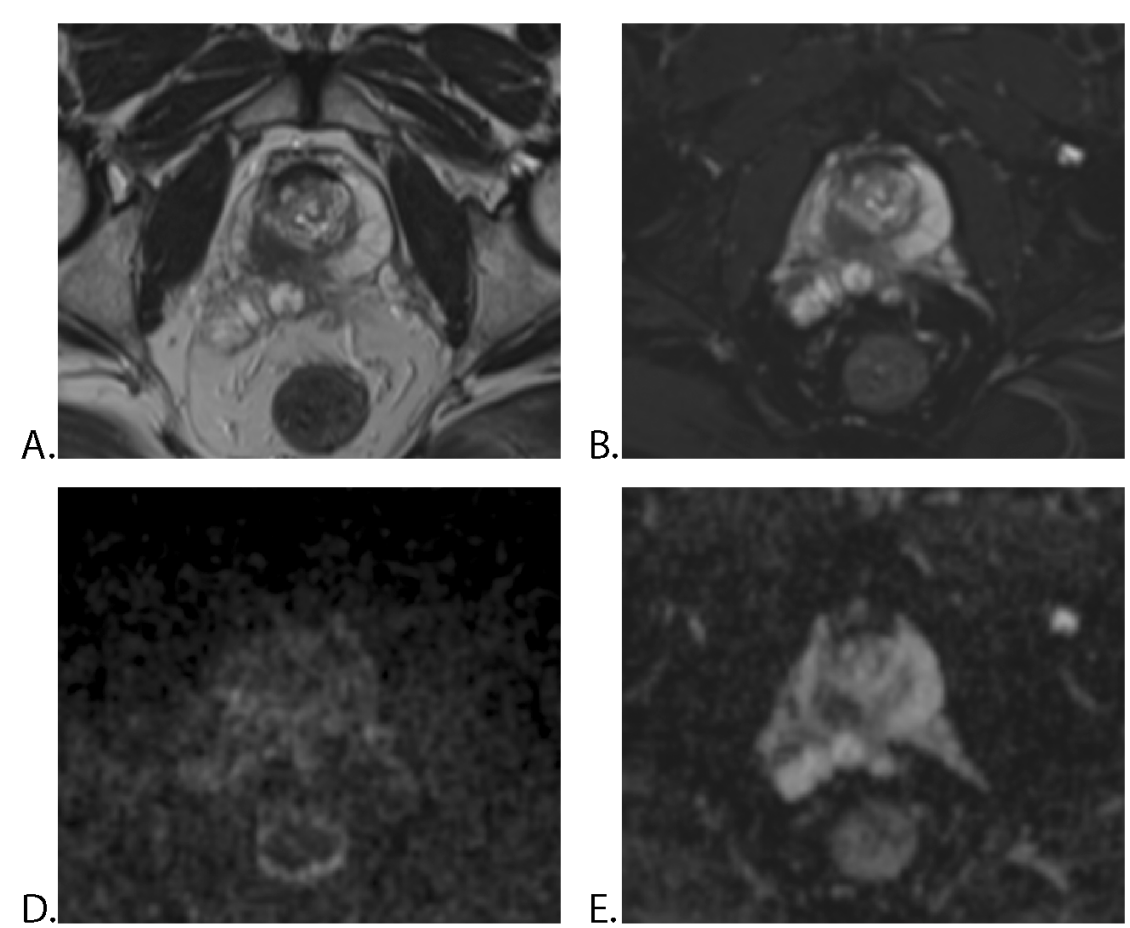
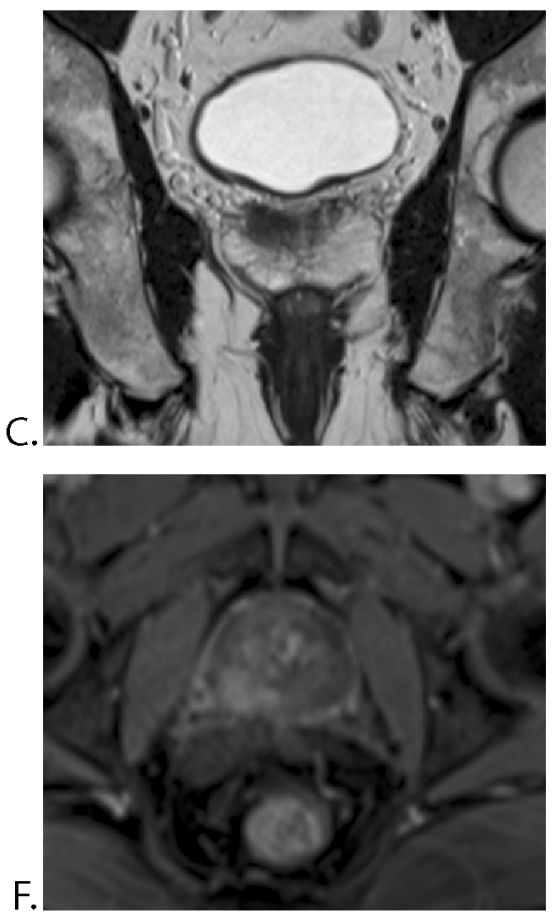

Figure 4. 57-year-old man with a PSA level of $9.0 \mathrm{ng} / \mathrm{ml}$ : mp-MRI without ERC (no prior prostate biopsy). A. Axial T2WI TSE, B. Axial T2WI fat-sat TSE and C. Coronal T2WI TSE showing a hypointense mass in the peripheral zone of the right prostatic lobe. D. Axial DWI image and E. ADC map demonstrates mildly hyperintense signal on high b-value (b 1200) and markedly hypointense mass on ADC, with early enhancement on F. DCE-MRI. All three radiologists reported a mass with extraprostatic extension and right seminal vesicle invasion. TRUS-guided biopsy performed after mp-MRI was positive for prostate cancer in the right gland with a Gleason score of 7 $(3+4)$. Histopathological analysis after radical prostatectomy confirmed right seminal vesicle invasion by the prostatic adenocarcinoma (T3b).

PSA $=$ prostate-specific antigen, mp-MRI $=$ multiparametric MRI, ERC $=$ endorectal coil, $\mathrm{TSE}=$ turbo spin echo, TRUS $:$ transrectal ultrasonography.

\section{Discussion}

We evaluated the interobserver agreement among three radiologists with similar level of experience, to detect EPE and SVI on mp-MRI using histopathological examination on radical prostatectomy specimens as reference standard. Overall $\mathrm{Se}$ in the assessment of EPE varied according to reader, ranging from $76.5 \%$ to $94.1 \%$ and overall $\mathrm{Sp}$ varied from $45.5 \%$ to $84.9 \%$. The overall accuracy rates for EPE also varied among readers and ranged between $58 \%$ and $88 \%$ with fair to good interobserver agreement. Se was however excellent and the accuracy rates improved when only the group with mpMRI performed before prostate biopsy was analyzed. Interreader agreement also improved in this group compared to the overall population, with kappa values showing moderate to very good agreement. In the subset of patients with TRUS-guided biopsy performed prior to mp-MRI, all readers reported lower values, Se ranging between $60 \%$ $90 \%$ and Sp between $42.3 \%-80.8 \%$; we hypothesize that these results may be due to post-biopsy changes, including hemorrhagic findings in the prostate.

Our results are in line with previous reports from the literature [21,22]. In a retrospective study on 106 patients examined with combined endorectal and pelvis phasedarray coils at $1.5 \mathrm{~T}$ MRI by 3 independent radiologists, Graser et al. [21] reported a moderate to good interobserver agreement in detecting extracapsular extension. All 3 observers reached comparable overall staging accuracies: per-patient Se for the recognition of T3 varied between $84.5-91 \%$ and $\mathrm{Sp}$ between 78.2-83.2\%; interobserver agreement ranged from 0.59 to 0.67 for the detection of EPE. In a prospective study on 101 patients, Rennard-Penna et al. [22] noticed a k-index of interobserver agreement of 0.56 , for diagnosing extracapsular disease, between 2 radiologists with different level of experience; patients were examined on $1.5 \mathrm{~T}$ MRI with pelvis phased-array coil before radical prostatectomy.

Consistent with other studies, we report moderate 
to good sensitivities and high specificities in detecting SVI in all readers: overall Se ranged between $57.1-85.7 \%$ and overall Sp between 86.1-97.7\%. PPV varied between 40$85.7 \%$ and NPV from $92.5-97.7 \%$. The overall interobserver agreement ranged from moderate to good. Comparable data in detecting SVI at $1.5 \mathrm{~T}$ were previously reported by Kim et al. - Se of $83 \%$, Sp of $92.3 \%$, PPV $71.4 \%$ and NPV of $96 \%$ [23].

The accuracy of SVI detection varied in our study, according to the use of ERC during mp-MRI. Se and NPV were higher in the group examined with ERC, for readers 1 and 2; thus, the probability of false negative results was lower in this series of patients, influencing the therapeutic approach. On the other hand, the accuracy rate improved in the group examined without endorectal coil, with excellent $\mathrm{Sp}$ and PPV for all three readers. Interobserver agreement was also better in the group examined without ERC (good to very good agreement). In a diagnostic meta-analysis including 75 studies (of which 18 were prospective) and 9796 patients, de Rooij et al. [3] reported a better accuracy for 1.5T MRI when using ERC in detecting SVI: Se $62 \%$ and Sp $97 \%$ in the studies performed with ERC compared to Se $37 \%$ and Sp $94 \%$ in the studies without ERC. Authors reported higher Se for the examinations performed without ERC when $3 \mathrm{~T}$ scanners were used (Se $65 \%$ without ERC vs. Se $45 \%$ with ERC) [3].

In our study, the accuracy in detecting EPE improved and we observed a better agreement between readers in the group examined without ERC (moderate to very good agreement) compared to the group with ERC (poor to moderate agreement). In the series of patients that performed mp-MRI without ERC (27 patients), Se in detecting EPE was $87.5 \%$ for all readers and Sp ranged between $52.6 \%$ and $94.7 \%$. Kim et al. [23] reported comparable accuracy in detecting EPE, with Se of $82.4 \%$ and $\mathrm{Sp}$ of $87.2 \%$, in a retrospective study with preoperative surface coil 1.5T MRI, including 32 intermediate and highrisk patients, reviewed by a single radiologist. With regards to the effect on accuracy when using the ERC for detecting EPE, recent studies reported similar Se and Sp between MRI examinations performed with and without ERC at $1.5 \mathrm{~T}$ and $3 \mathrm{~T}[1,3]$. ERC may be useful for a field strength of $1.5 \mathrm{~T}$ or in the absence of multiparametric examination; however, studies that used higher magnetic field strength or additional functional techniques with ERC had lower Se than studies without ERC [1,3].

Our study has several limitations. First, all readers were aware about the presence of prostate cancer in most of cases (36/50 patients); therefore, differentiation of inflammatory changes and cancer foci may have been affected. Positive MRI was reported per patient and not per region and this might be a potential factor that influenced our results. Post-biopsy hemorrhage was reported in $63.9 \%$ of our patients and these findings produced discrepancies between MRI reports and histopathology results. Another limitation is the relative small number of patients included in this single center study; thus, our results cannot be generalized and further studies on larger groups of patients are needed to confirm our findings.

In conclusion, mp-MRI at $1.5 \mathrm{~T}$ is a reliable imaging technique for the local staging of prostate cancer, with good diagnostic performance in detecting EPE and SVI. Our results showed overall interobserver rates of agreement between readers with the same level of experience in prostate MRI ranging from fair to good in the evaluation of EPE and from moderate to good for the assessment of SVI.

\section{References}

1. Kim BS, Kim TH, Kwon TG, Yoo ES. Comparison of pelvic phased-array versus endorectal coil magnetic resonance imaging at 3 Tesla for local staging of prostate cancer. Yonsei Med J. 2012;53:550-556.

2. Nishimoto K, Nakashima J, Hashiguchi A, Kikuchi E, Miyajima A, Nakagawa K, et al. Prediction of extraprostatic extension by prostate specific antigen velocity, endorectal MRI, and biopsy Gleason score in clinically localized prostate cancer. Int J Urol. 2008; 15:520-523.

3. de Rooij M, Hamoen EH, Witjes A, Barentsz JO, Rovers MM. Accuracy of Magnetic Resonance Imaging for local staging of prostate cancer detection: a diagnostic metaanalysis. Eur Urol. 2016;70:233-245.

4. Couñago F, Recio M, Del Cerro E, Cerezo L, Díaz Gavela A, Marcos FJ, et al. Role of 3.0 T multiparametric MRI in local staging in prostate cancer and clinical implications for radiation oncology. Clin Transl Oncol. 2014;16:993-999.

5. Sciarra A, Barentsz J, Bjartell A, Eastham J, Hricak H, Panebianco V, et al. Advances in magnetic resonance imaging: how they are changing the management of prostate cancer. Eur Urol. 2011;59:962-977.

6. Hoeks CM, Barentsz JO, Hambrock T, Yakar D, Somford DM, Heijmink SW, et al. Prostate cancer: multiparametric MR imaging for detection, localization, and staging. Radiology. 2011;261:46-66.

7. Mullerad M, Hricak H, Kuroiwa K, Pucar D, Chen HN, Kattan MW, et al. Comparison of endorectal magnetic resonance imaging, guided prostate biopsy and digital rectal examination in the preoperative anatomical localization of prostate cancer. J Urol. 2005;174:2158-2163.

8. Sala E, Akin O, Moskowitz CS, Eisenberg HF, Kuroiwa K, Ishill NM, et al. Endorectal MR imaging in the evaluation of seminal vesicle invasion: diagnostic accuracy and multivariate feature analysis. Radiology. 2006;238:929-937.

9. Wang L, Mullerad M, Chen HN, Eberhardt SC, Kattan MW, Scardino PT, et al. Prostate cancer: incremental value of endorectal MR imaging findings for prediction of extracapsular extension. Radiology. 2004;232:133-139.

10. Mullins JK, Bonekamp D, Landis P, Begum H, Partin AW, Epstein JI, et al. Multiparametric magnetic resonance imaging findings in men with low-risk prostate cancer followed using active surveillance. BJU Int. 2013;111:10371045. 
11. Davis R, Salmasi A, Koprowski C, Kim S, Kwon YS, Faiena I, et al. Accuracy of multiparametric Magnetic Resonance Imaging for extracapsular extension of prostate cancer in community practice. Clin Genitourin Cancer. 2016;14:e617-e622.

12. Bloch BN, Genega EM, Costa DN, Pedrosa I, Smith MP, Kressel HY, et al. Prediction of prostate cancer extracapsular extension with high spatial resolution dynamic contrastenhanced 3-T MRI. Eur Radiol. 2012;22:2201-2210.

13. Jeong IG, Lim JH, You D, Kim MH, Choi HJ, Kim JK, et al. Incremental value of magnetic resonance imaging for clinically high risk prostate cancer in 922 radical prostatectomies. J Urol. 2013;190:2054-2060.

14. Somford DM, Hamoen EH, Fütterer JJ, van Basten JP, Hulsbergen-van de Kaa CA, Vreuls W, et al. The predictive value of endorectal 3 Tesla multiparametric magnetic resonance imaging for extraprostatic extension in patients with low, intermediate and high risk prostate cancer. J Urol. 2013;190:1728-1734.

15. Otto J, Thörmer G, Seiwerts M, Fuchs J, Garnov N, Franz T, et al. Value of endorectal magnetic resonance imaging at $3 \mathrm{~T}$ for the local staging of prostate cancer. Rofo. 2014;186:795802.

16. Soylu FN, Peng Y, Jiang Y, Wang S, Schmid-Tannwald C, Sethi I, et al. Seminal vesicle invasion in prostate cancer: evaluation by using multiparametric endorectal MR imaging. Radiology. 2013;267:797-806.

17. Hull GW, Rabbani F, Abbas F, Wheeler TM, Kattan MW,
Scardino PT. Cancer control with radical prostatectomy alone in 1,000 consecutive patients. J Urol. 2002;167(2 Pt 1):528-534.

18. Barentsz JO, Richenberg J, Clements R, Choyke P, Verma $\mathrm{S}$, Villeirs G, et al. ESUR prostate MR guidelines 2012. Eur Radiol. 2012;22:746-757.

19. Weinreb JC, Barentsz JO, Choyke PL, Cornud F, Haider MA, Macura KJ, et al. PI-RADS Prostate Imaging - Reporting and Data System: 2015, Version 2. Eur Urol. 2016;69:16-40.

20. Compton CC, Byrd DR, Garcia-Aguillar J, et al. Prostate. In: AJCC Cancer Staging Atlas: A Companion to the Seventh Editions of the AJCC Cancer Staging Manual and Handbook. 2nd ed. New York: Springer; 2012: pp. 535-545.

21. Graser A, Heuck A, Sommer B, Massmann J, Scheidler $\mathrm{J}$, Reiser M, et al. Per-sextant localization and staging of prostate cancer: correlation of imaging findings with wholemount step section histopathology. AJR Am J Roentgenol. 2007; 188:84-90.

22. Renard-Penna R, Rouprêt M, Comperat E, Ayed A, Coudert M, Mozer P, et al. Accuracy of high resolution (1.5 tesla) pelvic phased array magnetic resonance imaging (MRI) in staging prostate cancer in candidates for radical prostatectomy: results from a prospective study. Urol Oncol. 2013;31:448-454.

23. Kim B, Breau RH, Papadatos D, Fergusson D, Doucette S, Cagiannos I, et al. Diagnostic accuracy of surface coil magnetic resonance imaging at $1.5 \mathrm{~T}$ for local staging of elevated risk prostate cancer. Can Urol Assoc J. 2010;4:257262. 